\title{
The Influential Factors to Achieve High Modulus Fibers and Injection Molded Specimens of Polyarylates
}

\author{
Toshihide Inoue, ${ }^{*}$ Norikazu Tabata, and Toru YamanaKa \\ Toray Industries, Inc., Plastics Research Laboratories, \\ 9-1 Oe-cho, Minato-ku, Nagoya 455, Japan \\ (Received October 2, 1995)
}

\begin{abstract}
Various polyarylates from substituted hydroquinones (HQs) and substituted 1,2-bis(phenoxy)ethane-4,4'dicarboxylic acids (PECs) or 4,4'-diphenyldicarboxylic acid (BB) were prepared. Thermal properties, orientation function of nematic domains ( $F$ value) and morphology of fibers and injection molded specimens of them were investigated. From these results, it is assumed that the stability of liquid crystallinity, rigidity of the polymer chain and $F$ value are the important factors determining the modulus of fibers. On the other hand, the stability of liquid crystallinity, rigidity of the polymer chain and packing density of the polymer chain are assumed to be the influential factors to determine the modulus of injection molded specimens.
\end{abstract}

KEY WORDS Polyarylates / Liquid Crystallinity / Modulus / Fibers / Injection Molded Specimens / Orientation Function / 1,2-Bis(phenoxy)ethane-4,4'-dicarboxylic Acid / 4,4'-Diphenyl-dicarboxylic Acid (BB) /

Recently thermotropic liquid crystalline polyarylates (LCPs) have been attracting much attention because of their very high modulus. Many researchers reported the structure-thermal property correlations in LCPs from substituted hydroquinones (HQs) and dicarboxylic acid. Lenz et al. investigated the liquid crystallinity of the polyarylates from substituted HQs and terephthalic acid (TA), ${ }^{1-5}$ substituted HQs and 1,10-bis(phenoxy)decane$4,4^{\prime}$-dicarboxylic acid, ${ }^{6}$ and substituted HQs and $\alpha, \omega$ bis(phenoxy)alkane-4,4'-dicarboxylic acid. ${ }^{7}$ Kricherdorf and Osman reported the liquid crystallinity of the polyarylates from substituted HQs and 1,4-cyclohexanedicarboxylic acid. ${ }^{8,9}$ Krigbaum and Heitz investigated the liquid crystallinity of the polyarylates from substituted HQs and substituted TA. ${ }^{10-12}$ Jackson reported the liquid crystallinity and the moduli of fibers and injection molded specimens of the polyarylates from substituted HQs and TA. ${ }^{13}$ However, the influential factors to obtain high modulus fibers and injection molded specimens are not reported enough.

We have been working on the preparation of novel LCPs from substituted HQs and substituted 1,2-bis(phenoxy)ethane-4, $4^{\prime}$-dicarboxylic acids (PECs), ${ }^{14}$ and substituted HQs and 4,4'-diphenyldicarboxylic acid (BB). ${ }^{15,16}$ Here, we would like to report the investigation on the relationship between the chemical structures and moduli, and the influential factors to achieve the high moduli of as-spun fibers and injection molded specimens of these polyarylates.

\section{EXPERIMENTAL}

\section{Synthesis of Polyarylates}

Polyarylates were prepared from substituted HQ diacetates, substituted PECs and BB by melt polymerization at $250-400^{\circ} \mathrm{C}$. The pressure was gradually reduced to 1 Torr as polymerization proceeded.

\footnotetext{
† To whom correspondence should be addressed.
}

\section{Preparation of Fibers}

Polymers were melt spun by using a flow tester having a capillary with a diameter of 0.3 or $0.5 \mathrm{~mm}$.

\section{Preparation of Specimens}

The specimens for the measurements of flexural modulus were prepared by injection molding using a Sumitomo NESTAL injection molding machine $(0.5$ ounce).

\section{MEASUREMENTS}

\section{Flexural Modulus}

A TOYO Boldwin Tensilon UTM-4-200 was used for the measurements. The measurements were performed according to ASTM D790 using injection molded specimens with thickness of $1 / 32$ inch.

\section{Dynamic Storage Modulus}

A TOYO Boldwin Reovibron Viscoelastometer Rheo2000/3000 was used for the measurements. The measurements were performed at a frequency of $110 \mathrm{~Hz}$, a heating rate of $2^{\circ} \mathrm{C} \mathrm{min}^{-1}$ and an interchuck distance of $40 \mathrm{~mm}$.

\section{Anisotropic Melting Temperature $\left(T_{\mathrm{n}}\right)$ and Cleaning Point $\left(T_{\mathrm{i}}\right)$}

A hot stage equipped with a polarizing microscope was used for the measurements. $T_{\mathrm{n}}$ was determined as the onset temperature of stir-opalescence observed on the hot stage. Liquid crystalline-to-isotropic transition temperature $\left(T_{\mathrm{i}}\right)$ also could be determined by the use of the hot stage.

\section{Melting Temperature $\left(T_{\mathrm{m}}\right)$ and Glass Transition Tempera- ture $\left(T_{\mathrm{g}}\right)$}

A Perkin-Elmer DSC-7 was used for the measurements. The measurements were performed in a $\mathrm{N}_{2}$ atmosphere with a heating rate of $20^{\circ} \mathrm{C} \mathrm{min}^{-1}$. 
Orientation Function of Nematic Domains (F Value)

$F$ value of as-spun fibers were calculated according to eq 1 .

$$
F=\left(3\left\langle\cos ^{2} \theta\right\rangle_{\mathrm{av}}-1\right) / 2
$$

$\theta$ values were measured by wide-angle $\mathrm{X}$-ray diffractometry. $F=1$ means that the domains are perfectly alined along the flow direction, while $F=0$ means that the domains are randomly distributed.

\section{Morphology}

Morphology of tensile fractured as-spun fibers and the flexural injection molded specimens were studied by scanning electron microscopy (SEM).

\section{RESULTS AND DISCUSSION}

\section{As-Spun Fibers}

The liquid crystallinity and the moduli of as-spun fibers of polyarylates from substituted HQs and substituted PECs could be controlled by the substituents as shown in Table I. Polyarylates derived from $t$-butyl HQ ( $t$ Bu-HQ) and PEC ( $t$ Bu-HQ/PEC), phenyl-HQ and

Table I. Thermal properties and modulus of substituted HQs/PEC and substituted HQs/Cl-PEC fibers ${ }^{\mathrm{a}}$

\begin{tabular}{|c|c|c|c|c|c|c|}
\hline \multicolumn{2}{|c|}{ Polymer } & \multicolumn{3}{|c|}{ Thermal properties } & \multirow{2}{*}{$\frac{d^{\mathrm{b}}}{\mathrm{mm}}$} & \multirow{2}{*}{$\frac{\text { Modulus }}{\mathrm{GPa}}$} \\
\hline $\mathrm{X}$ & Acid & $T_{\mathrm{g}} /{ }^{\circ} \mathrm{C}$ & $T_{\mathrm{n}} /{ }^{\circ} \mathrm{C}$ & $T_{\mathrm{i}} /{ }^{\circ} \mathrm{C}$ & & \\
\hline $\mathrm{Cl}$ & PEC & 87 & 282 & $>350$ & 0.09 & 48 \\
\hline $\mathrm{Cl}$ & Cl-PEC & 120 & 247 & $>350$ & 0.06 & 68 \\
\hline $\mathrm{Me}$ & PEC & 104 & 265 & $>350$ & 0.06 & 42 \\
\hline $\mathrm{Me}$ & Cl-PEC & 129 & 303 & $>350$ & 0.11 & 72 \\
\hline$t \mathrm{Bu}$ & PEC & 146 & 240 & 316 & 0.06 & 36 \\
\hline$t \mathrm{Bu}$ & Cl-PEC & 141 & \multicolumn{2}{|c|}{ (Isotropic) } & 0.06 & 5 \\
\hline $\mathrm{Ph}$ & PEC & 124 & 235 & 265 & 0.07 & 26 \\
\hline $\mathrm{Ph}$ & Cl-PEC & 115 & (Iso & pic) & 0.08 & 4 \\
\hline $\mathrm{Ch}$ & PEC & 139 & (Iso & pic) & 0.07 & 8 \\
\hline $\mathrm{Ch}$ & Cl-PEC & 133 & (Iso & pic) & 0.11 & 3 \\
\hline
\end{tabular}

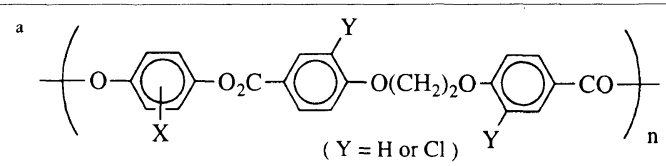

${ }^{\mathrm{b}}$ Diameters of as-spun fibers.

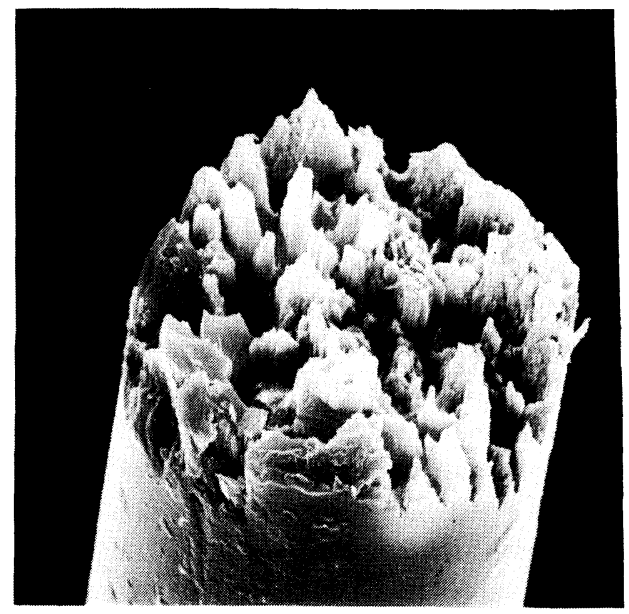

(I)
PEC (Ph-HQ/PEC) showed decreased liquid crystallinity compared to chloro-HQ and PEC (Cl-HQ/PEC), and methyl-HQ and PEC (Me-HQ/PEC) because of the bulky substituents on HQ units.

Therefore, the moduli of as-spun fibers of $t \mathrm{Bu}-\mathrm{HQ} /$ $\mathrm{PEC}$ and $\mathrm{Ph}-\mathrm{HQ} / \mathrm{PEC}$ were lower than those of $\mathrm{Cl}-$ HQ/PEC and Me-HQ/PEC. ${ }^{14,18,19}$ Tensile fractured asspun fibers of $\mathrm{Ph}-\mathrm{HQ} / \mathrm{PEC}$ exhibited decreased orientation of fibrils compared to $\mathrm{Me}-\mathrm{HQ} / \mathrm{PEC}$ as shown in Figure 1. Polyarylates from cyclohexyl-HQ (Ch-HQ) and PEC (Ch-HQ/PEC) did not show liquid crystallinity due to the more bulky substituent on the HQ unit than those of $t \mathrm{Bu}-\mathrm{HQ}$ and $\mathrm{Ph}-\mathrm{HQ}$. The moduli of as-spun fibers of $\mathrm{Ch}-\mathrm{HQ} / \mathrm{PEC}$ exhibited lower moduli than those of $t \mathrm{Bu}-\mathrm{HQ} / \mathrm{PEC}$ and $\mathrm{Ph}-\mathrm{HQ} / \mathrm{PEC}$. Therefore, in order to obtain high modulus as-spun fibers, the stability of liquid crystallinity $\left(T_{\mathrm{i}}-T_{\mathrm{n}}\right)$ is an influential factor as shown in Table I.

On the other hand, the moduli of as-spun fibers of polyarylates from Cl-HQ and 1,2-bis(2-chlorophenoxy)ethane-4,4'-dicarboxylic acid (Cl-PEC) (Cl-HQ/Cl-PEC) and Me-HQ and Cl-PEC (Me-HQ/Cl-PEC) were higher than those of Cl-HQ/PEC and Me-HQ/PEC. The reason for higher moduli appeared to be the increased rigidity of the polymer chain caused by the restricted rotation of the ether-linkage of Cl-PEC due to the steric hindrance of $\mathrm{Cl}$. However, the moduli of polyarylates from $t \mathrm{Bu}-\mathrm{HQ}$ and $\mathrm{Cl}-\mathrm{PEC}(t \mathrm{Bu}-\mathrm{HQ} / \mathrm{Cl}-\mathrm{PEC})$, and $\mathrm{Ph}-\mathrm{HQ}$ and $\mathrm{Cl}$-PEC (Ph-HQ/Cl-PEC) were lower than those of $t \mathrm{Bu}-\mathrm{HQ} / \mathrm{PEC}$ and $\mathrm{Ph}-\mathrm{HQ} / \mathrm{PEC}$ because $t \mathrm{Bu}-\mathrm{HQ} / \mathrm{Cl}-$ $\mathrm{PEC}$ and $\mathrm{Ph}-\mathrm{HQ} / \mathrm{Cl}-\mathrm{PEC}$ did not show the liquid crystallinity due to the steric hindrance of $\mathrm{Cl}$ on PEC. Tensile fractured as-spun fibers of $\mathrm{Ph}-\mathrm{HQ} / \mathrm{Cl}-\mathrm{PEC}$ no longer exhibited fibrils which were different from $\mathrm{Ph}$ $\mathrm{HQ} / \mathrm{PEC}$ as shown in Figure 2. Thus, in order to obtain high modulus as-spun fibers, the stability of liquid crystallinity and the rigidity of the polymer chain are assumed to be influential factors.

Therefore, we expected that the polyarylates from substituted HQs and BB would show higher modulus than those from substituted HQs and substituted PEC.

However, as-spun fibers of the polyarylate from MeHQ and BB (Me-HQ/BB) exhibited a lower modulus than that of Me-HQ/Cl-PEC in spite of the more rigid

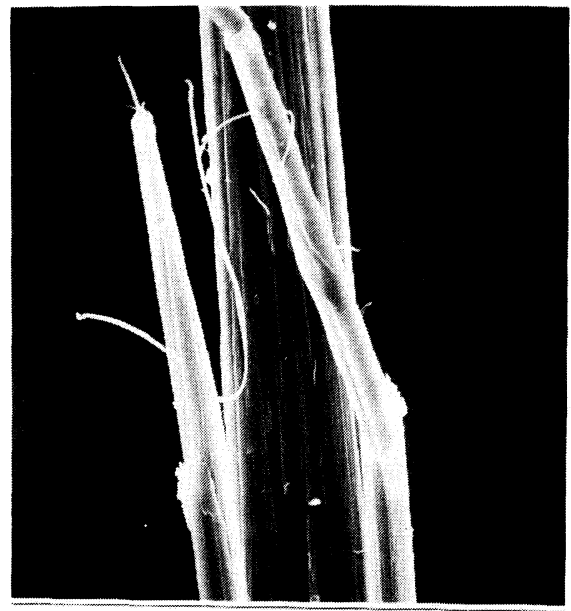

(II)

Figure 1. SEM of tensile fractured as-spun fibers of (I) Ph-HQ/PEC $(26 \mathrm{GPa}),(1000 \times)$ and (II) Me-HQ/PEC $(42 \mathrm{GPa}),(300 \times)$. 


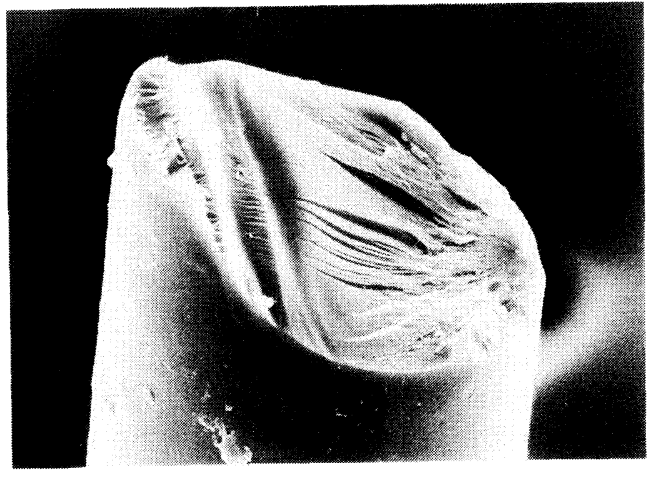

(I)

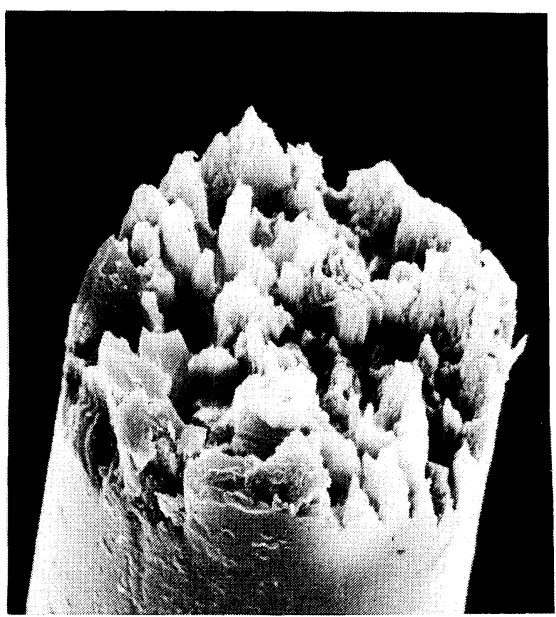

(II)

Figure 2. SEM of tensile fractured as-spun fibers of (I) Ph-HQ/Cl-PEC (4 GPa), $(500 \times)$ and (II) Ph-HQ/PEC (26 GPa), (1000 $\times)$.

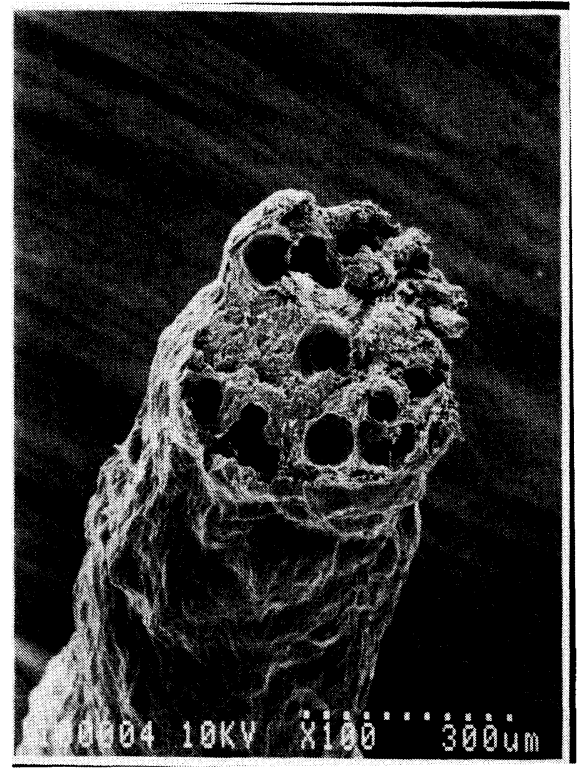

(I)

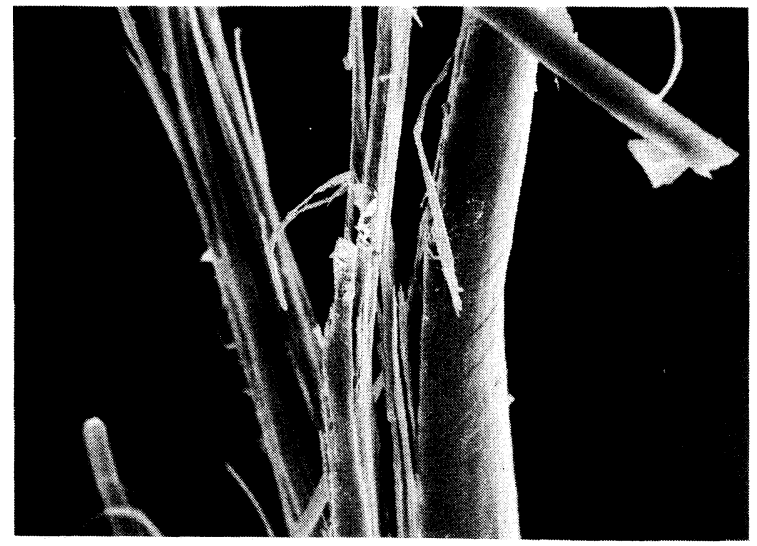

(II)

Figure 3. SEM of tensile fractured as-spun fibers of (I) Me-HQ/BB $\left(5 \mathrm{GPa}, F=0.62: T_{\mathrm{g}} 175^{\circ} \mathrm{C}\right),(100 \times)$ and $(\mathrm{II}) \mathrm{Me}-\mathrm{HQ} / \mathrm{Cl}-\mathrm{PEC}(72 \mathrm{GPa}, F=0.90$ : $\left.T_{\mathrm{g}} 129^{\circ} \mathrm{C}\right),(300 \times)$.

chemical structure. The lower modulus of $\mathrm{Me}-\mathrm{HQ} / \mathrm{BB}$ is referred to the lower $F$ value compared to $\mathrm{Me}-\mathrm{HQ} / \mathrm{Cl}-$ $\mathrm{PEC}$ due to the lower elongational flow orientation. Tensile fractured as-spun fibers of Me-HQ/BB exhibited decreased orientation of fibrils compared to $\mathrm{Me}-\mathrm{HQ} / \mathrm{Cl}-$ PEC as shown in Figure 3. ${ }^{15,20}$ The degree of elongational flow orientation was evaluated from the observed orientation of fibrils in the cross sections of tensile fractured as-spun fibers as shown in Figure 3.

As-spun fibers of the polyarylates from 2-chlorophenylhydroquinone (CP-HQ) and BB (CP-HQ/BB) exhibited higher modulus compared to $\mathrm{Me}-\mathrm{HQ} / \mathrm{BB}$, the higher modulus was referred to the higher $F$ values due to the higher elongational flow orientation. Tensile fractured as-spun fibers of CP-HQ/BB exhibited many fibrils compared to $\mathrm{Me}-\mathrm{HQ} / \mathrm{BB}$ as shown in Figure $4 .{ }^{15}$ Thus, the elongational flow orientation ( $F$ value) seems to be a more influential factor than the rigidity of the polymer chain and stability of liquid crystallinity to achieve a high modulus of as-spun fibers. In order to investigate the relationship between the moduli of asspun fibers and elongational flow orientation, $\mathrm{Cl}-\mathrm{HQ} /$ $\mathrm{BB}$ modified with TA (Cl-HQ/BB/TA) and Me-HQ/BB modified with 2,6-naphthalic dicarboxylic acid (NDA) (Me-HQ/BB/NDA) with various molar ratio were prepared. ${ }^{13,14}$ Although as-spun fibers of $\mathrm{Cl}-\mathrm{HQ} / \mathrm{BB} / \mathrm{TA}$ with $m / n=70 / 30$ exhibited a modulus of $95 \mathrm{GPa}$, asspun fibers of Cl-HQ/BB/TA with $m / n=80 / 20$ exhibited a lower modulus of only $11 \mathrm{GPa}$ in spite of the more rigid chemical structure due to the decreased elongational flow orientation. Tensile fractured as-spun fibers of Cl-HQ/BB/TA with $m / n=70 / 30$ exhibited many fibrils compared to $\mathrm{Cl}-\mathrm{HQ} / \mathrm{BB} / \mathrm{TA}$ with $m / n=80 / 20$ as shown in Figure 5. Although as-spun fibers of $\mathrm{Me}-\mathrm{HQ} / \mathrm{BB} /$ NDA with $m / n=92.5 / 7.5$ exhibited the modulus of $112 \mathrm{GPa}$, as-spun fibers of Me-HQ/BB/NDA with

Polym. J., Vol. 28, No. 5, 1996 


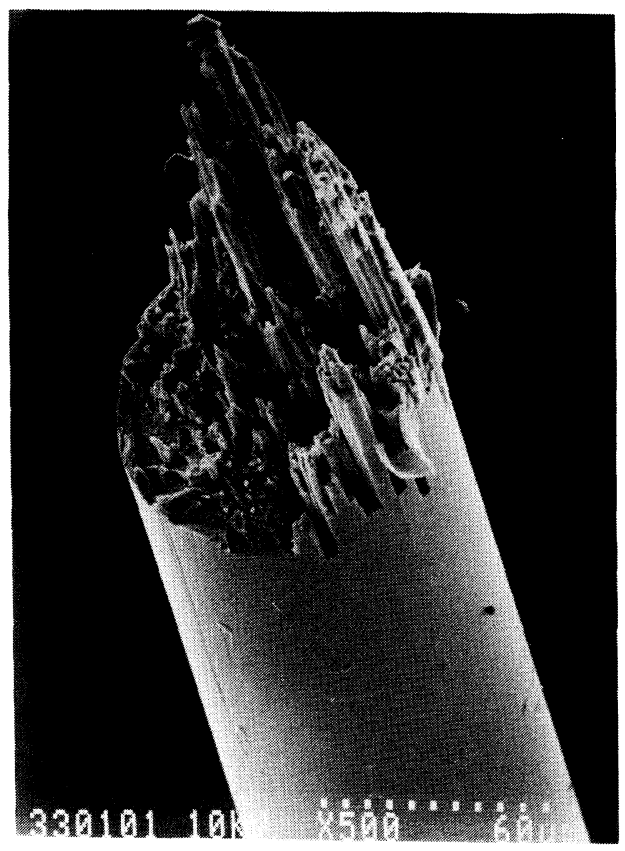

(I)

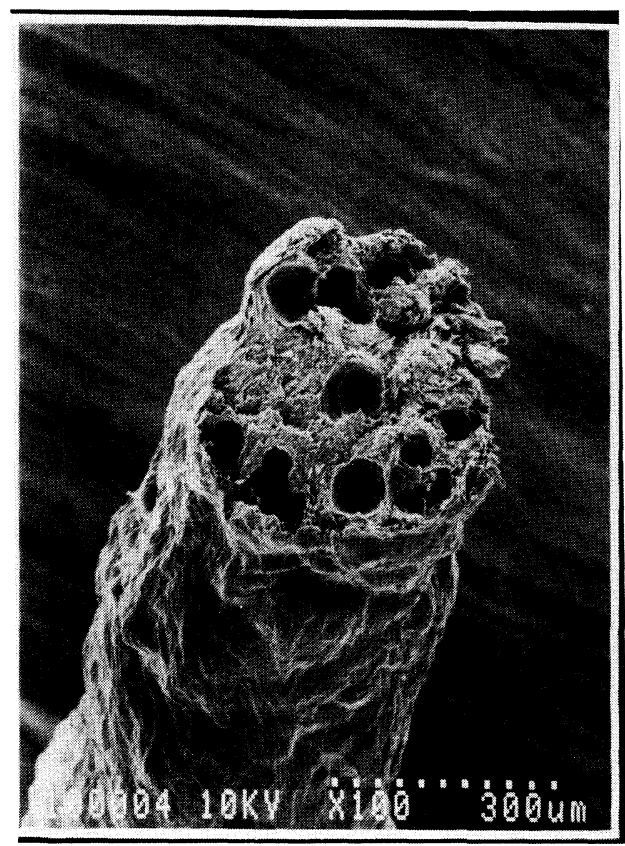

(II)

Figure 4. SEM of tensile fractured as-spun fibers of (I) CP-HQ/BB $(47 \mathrm{GPa}, F=0.90),(500 \times)$ and $(\mathrm{II}) \mathrm{Me}-\mathrm{HQ} / \mathrm{BB}(5 \mathrm{GPa}, F=0.62),(100 \times)$.

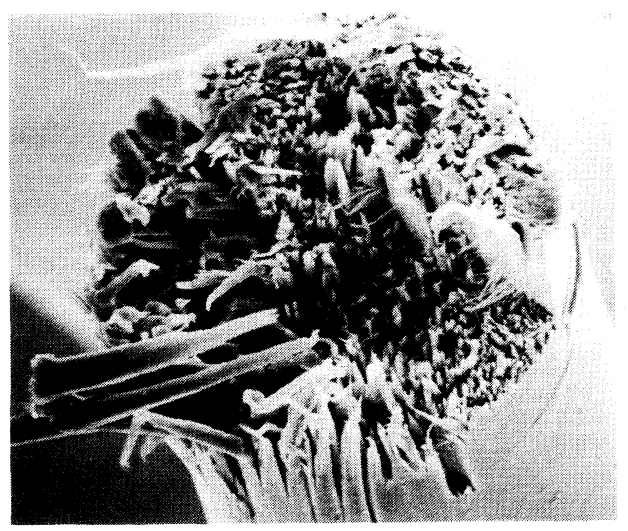

(I)

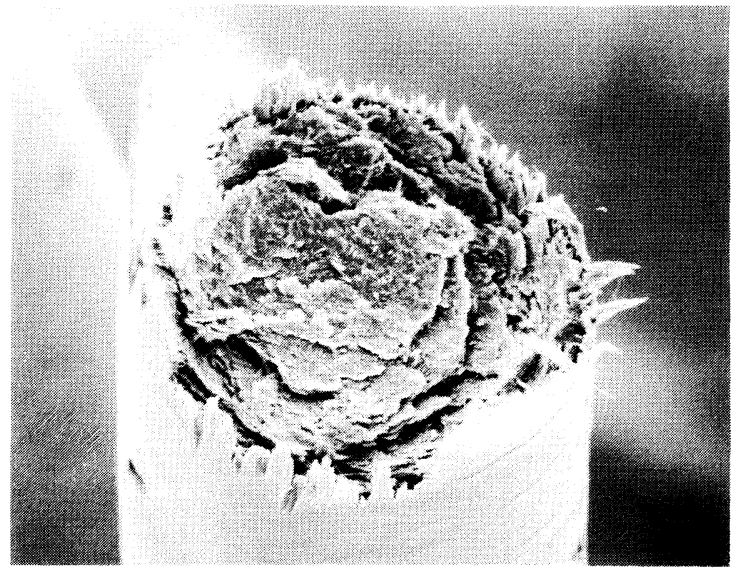

(II)

Figure 5. SEM of tensile fractured as-spun fibers of (I) Cl-HQ/BB/TA $(m / n=7 / 3,95 \mathrm{GPa}),(1000 \times)$ and (II) Cl-HQ/BB/TA $(m / n=8 / 2)(11 \mathrm{GPa})$, $(1000 \times))^{a}$

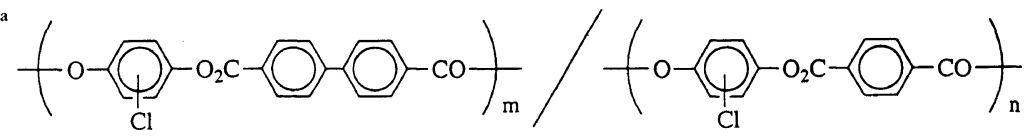

$m / n=95 / 5$ exhibited a lower modulus of only $19 \mathrm{GPa}$, the lower modulus is referred to the lower elongational flow orientation. Tensile fractured as-spun fibers of Me-HQ/BB/NDA with $m / n=92.5 / 7.5$ exhibited many fibrils compared to Me-HQ/BB/NDA with $m / n=95 / 5$ as shown in Figure 6.

Figure 7 shows the relationship between the moduli of as-spun fibers and $F$ values of substituted HQs/BB and substituted HQs/BB modified with 4,4'-dihydroxybiphenyl (DHB), NDA, Cl-PEC, and TA. ${ }^{21,16,22,23} \mathrm{We}$ observe that the modulus increases with the increase of $F$ value. Thus, influential factors to obtain high modulus of as-spun fibers are as follows: (1) the stability of liquid crystallinity; (2) the rigidity of polymer chain; (3) the Polym. J., Vol. 28, No. 5, 1996 degree of elongational flow orientation ( $F$ value).

\section{Injection Molded Specimens}

As as-spun fibers of Me-HQ/Cl-PEC showed higher modulus than $\mathrm{Ph}-\mathrm{HQ} / \mathrm{Cl}-\mathrm{PEC}$, the flexural modulus of injection molded specimens of Me-HQ/Cl-PEC exhibited a higher flexural modulus than that of $\mathrm{Ph}-\mathrm{HQ} / \mathrm{Cl}-\mathrm{PEC}$ due to the stability of liquid crystallinity. Though flexural fractured injection molded specimens of Me-HQ/Cl-PEC exhibited highly oriented fibrils, Ph-HQ/Cl-PEC no longer exhibited fibrils as shown in Figure 8.

Although as-spun fiber of $\mathrm{Me}-\mathrm{HQ} / \mathrm{BB}$ exhibited a lower modulus than that of Me-HQ/Cl-PEC, the flexural modulus of injection molded specimens of Me-HQ/BB 


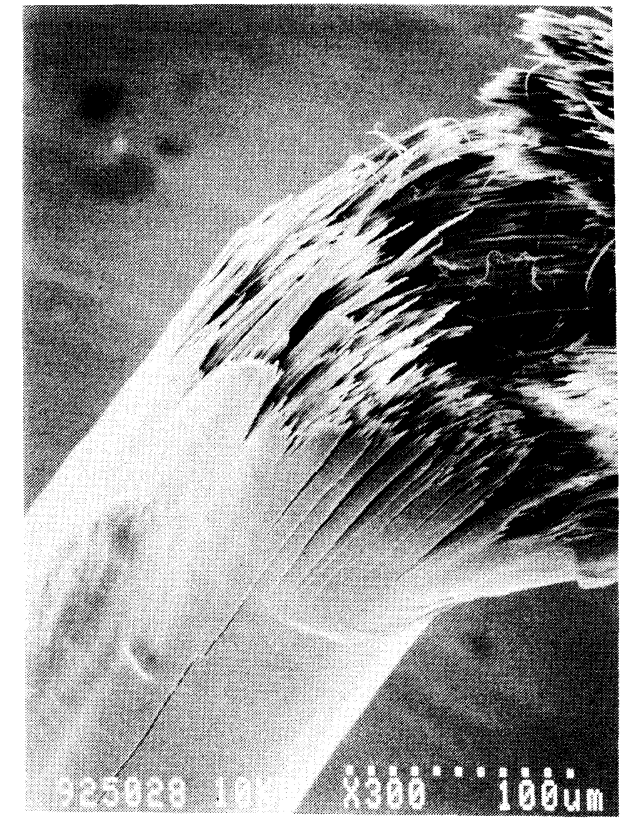

(I)

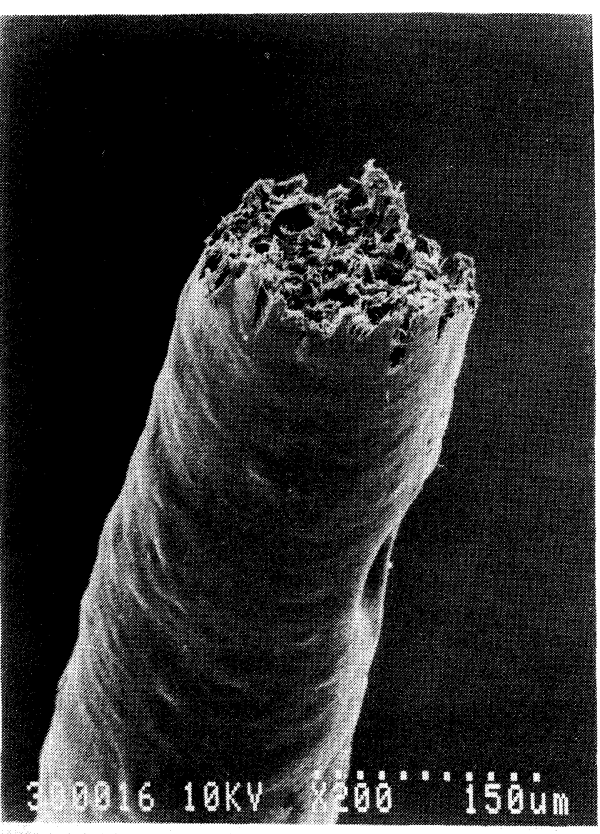

(II)

Figure 6. SEM of tensile fractured as-spun fibers of (I) Me-HQ/BB/NDA $(m / n=92.5 / 7.5)(112 \mathrm{GPa}, F=0.91),(300 \times)$ and (II) $\mathrm{Me}-\mathrm{HQ} / \mathrm{BB} / \mathrm{NDA}$ $(m / n=95 / 5)(19 \mathrm{GPa}, F=0.83),(200 \times){ }^{\mathrm{a}}$

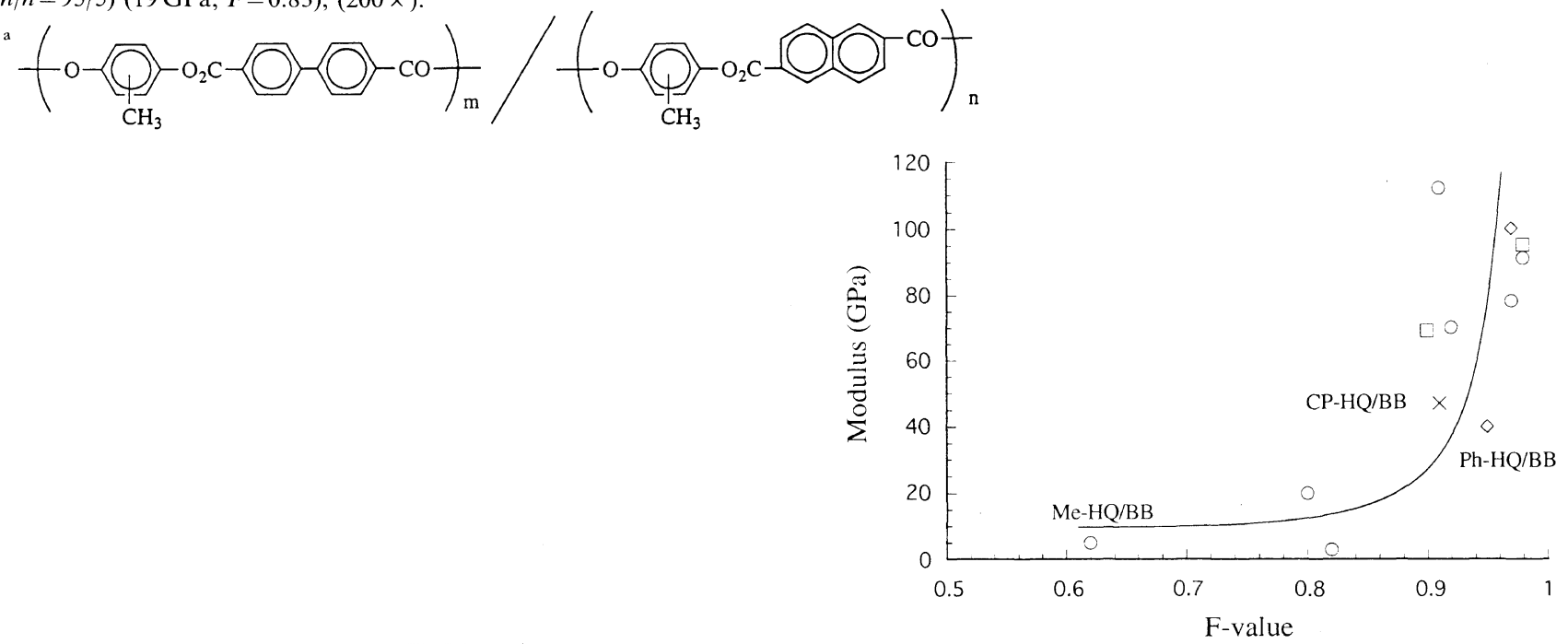

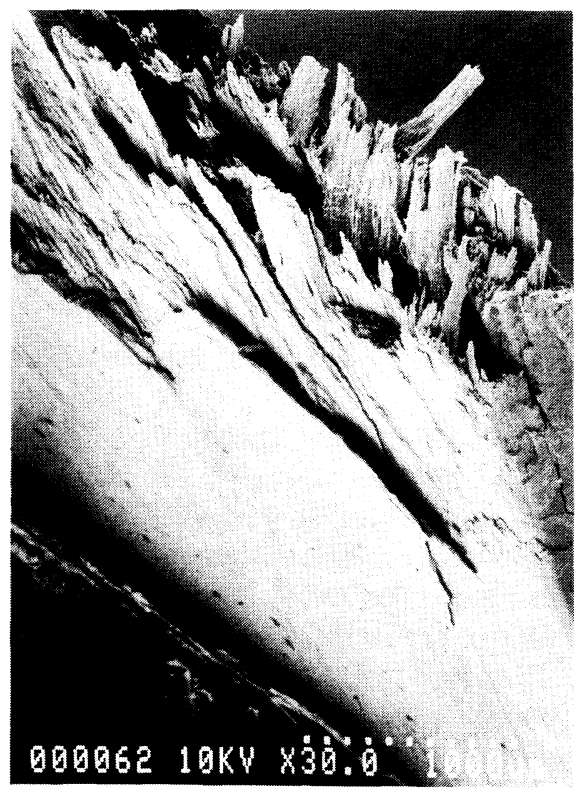

(I)

Figure 7. Modulus and $F$ of as-spun fibers. $O, \mathrm{Me}-\mathrm{HQ} / \mathrm{BB}$ and copolyarylates; $\square$, copolyarylates of $\mathrm{Cl}-\mathrm{HQ} / \mathrm{BB} ; \diamond, \mathrm{Ph}-\mathrm{HQ} / \mathrm{BB}$ and copolyarylates; $\times, \mathrm{CP}-\mathrm{HQ} / \mathrm{BB}$.

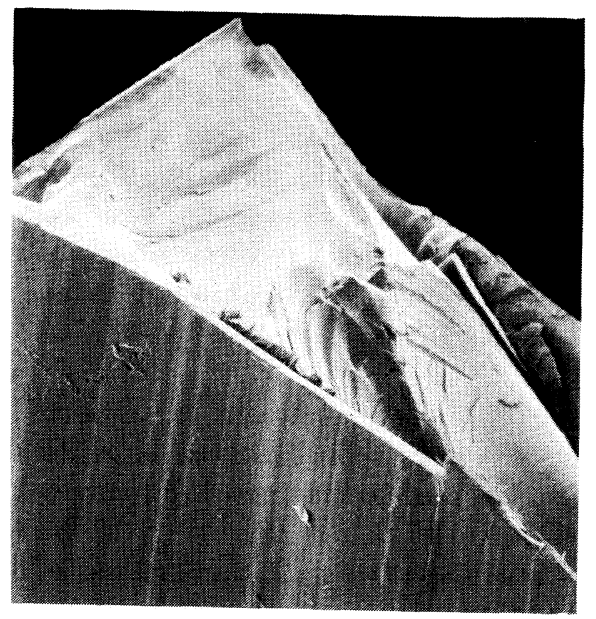

(II)

Figure 8. SEM of flexural fractured injection molded specimens of (I) Me-HQ/Cl-PEC $(15 \mathrm{GPa}),(30 \times)$ and (II) Ph-HQ/Cl-PEC $(7.5 \mathrm{GPa}),(100 \times)$ 


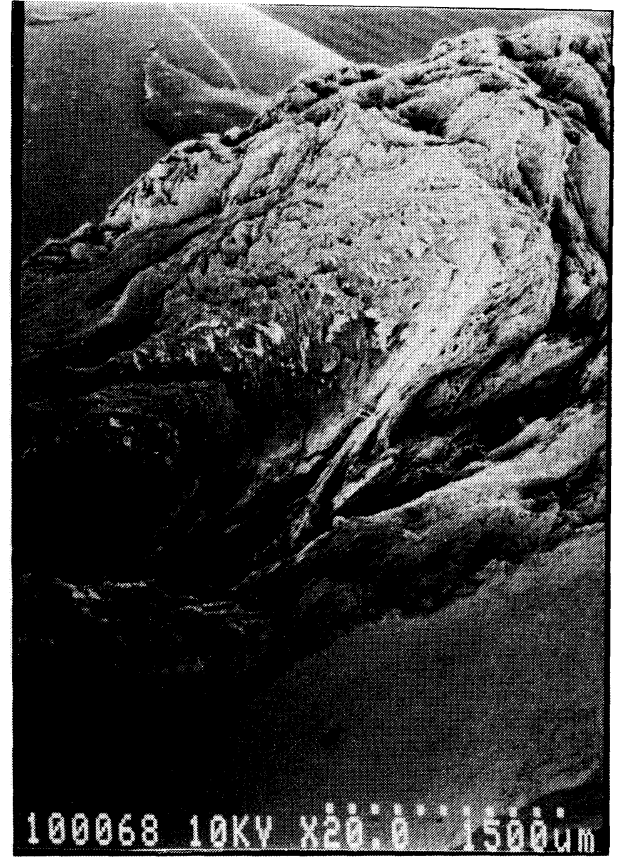

(I)

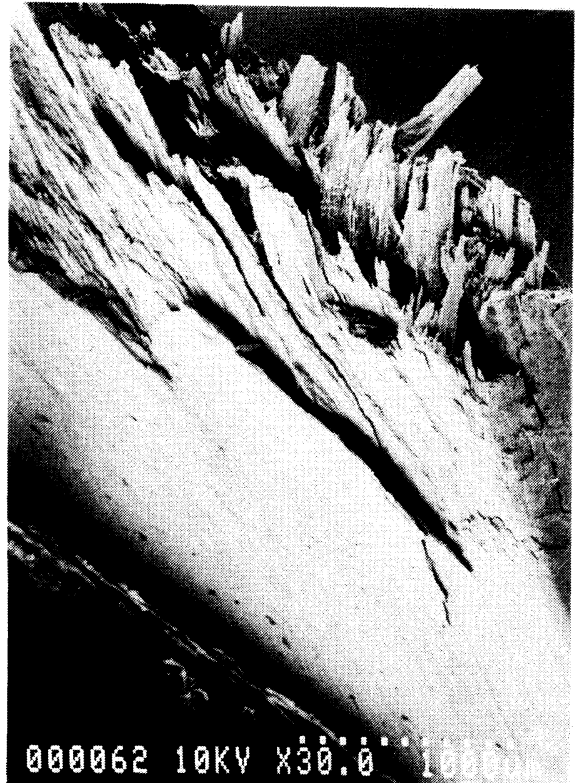

(II)

Figure 9. SEM of flexural fractured injection molded specimens of (I) Me-HQ/BB (31 GPa: $\left.T_{\mathrm{g}} 175^{\circ} \mathrm{C}\right),(20 \times)$ and (II) Me-HQ/Cl-PEC (15 GPa: $\left.T_{\mathrm{g}} 129^{\circ} \mathrm{C}\right),(30 \times)$.

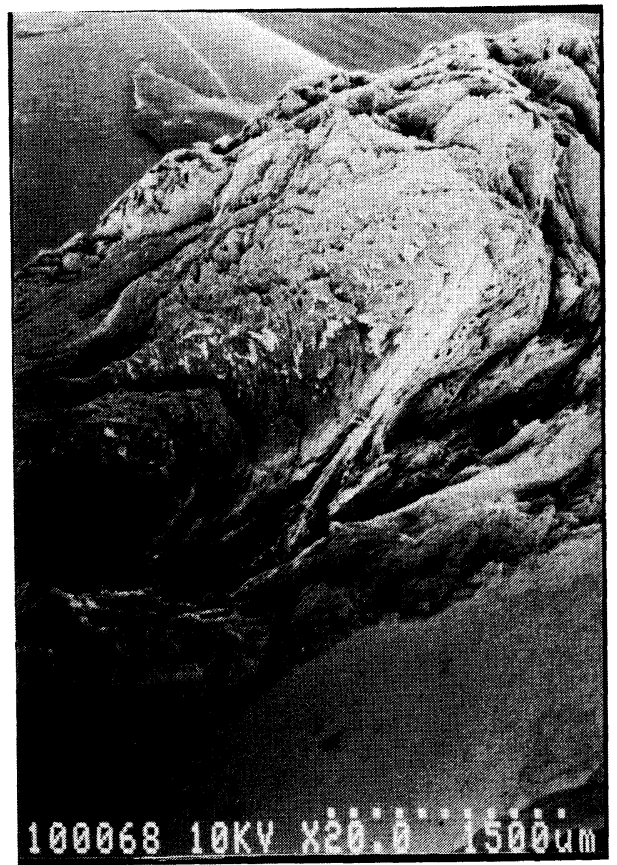

(I)

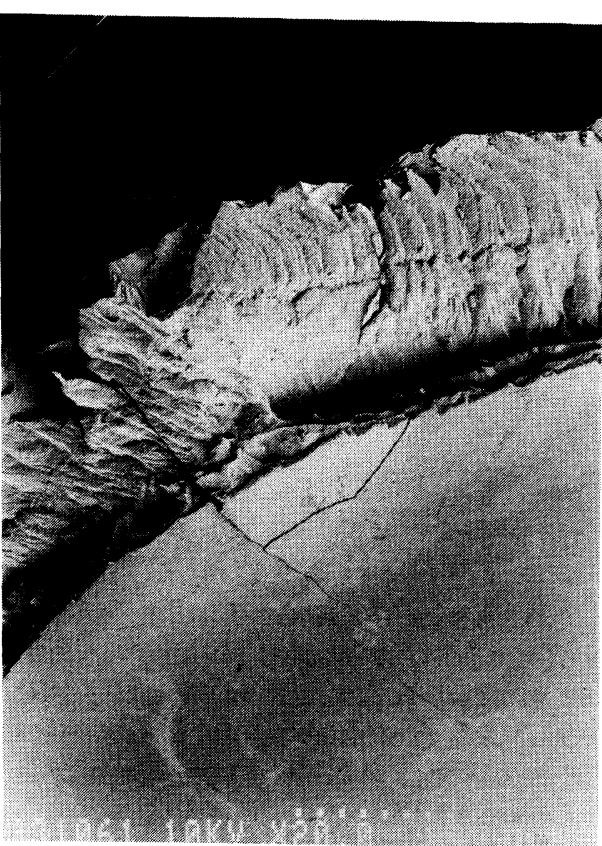

(II)

Figure 10. SEM of flexural fractured injection molded specimens of (I) Me-HQ/BB $\left(31 \mathrm{GPa}, F=0.62: T_{\mathrm{g}} 175^{\circ} \mathrm{C}\right),(20 \times)$ and (II) $\mathrm{CP}-\mathrm{HQ} / \mathrm{BB}$ $\left(20 \mathrm{GPa}, F=0.74: T_{\mathrm{g}} 196^{\circ} \mathrm{C}\right),(20 \times)$.

exhibited a higher flexural modulus than that of Me$\mathrm{HQ} / \mathrm{Cl}-\mathrm{PEC}$ due to the higher rigidity of the polymer chain in spite of the lower $F$ value. Flexural fractured injection molded specimens of $\mathrm{Me}-\mathrm{HQ} / \mathrm{BB}$ exhibited fewer fibrils than Me-HQ/Cl-PEC due to lower $F$ value as shown in Figure 9. The flexural modulus of injection molded specimens of $\mathrm{Me}-\mathrm{HQ} / \mathrm{BB}$ was higher than that of CP-HQ/BB in spite of the lower $F$ value and lower rigidity of the polymer chain (lower $T_{\mathrm{g}}$ ) as shown in Figure 10. In spite of the lower rigidity, the reason why Me-HQ/BB exhibited higher flexural modulus than Polym. J., Vol. 28, No. 5, 1996
$\mathrm{CP}-\mathrm{HQ} / \mathrm{BB}$ is the higher packing density of the polymer chain due to the decrease in the size of substituents of HQ. ${ }^{15}$ In order to investigate the relationship between the moduli of injection molded specimens and the elongational flow orientation ( $F$ values), Me-HQ/BB/ NDA with various molar ratio were prepared. Although as-spun fibers of $\mathrm{Me}-\mathrm{HQ} / \mathrm{BB} / \mathrm{NDA}$ with $m / n=95 / 5 \mathrm{ex}$ hibited a lower modulus than Me-HQ/BB/NDA with $m / n=92.5 / 7.5$, the flexural modulus of injection molded specimens of Me-HQ/BB/NDA with $m / n=95 / 5$ exhibited a higher flexural modulus than Me-HQ/BB/NDA 


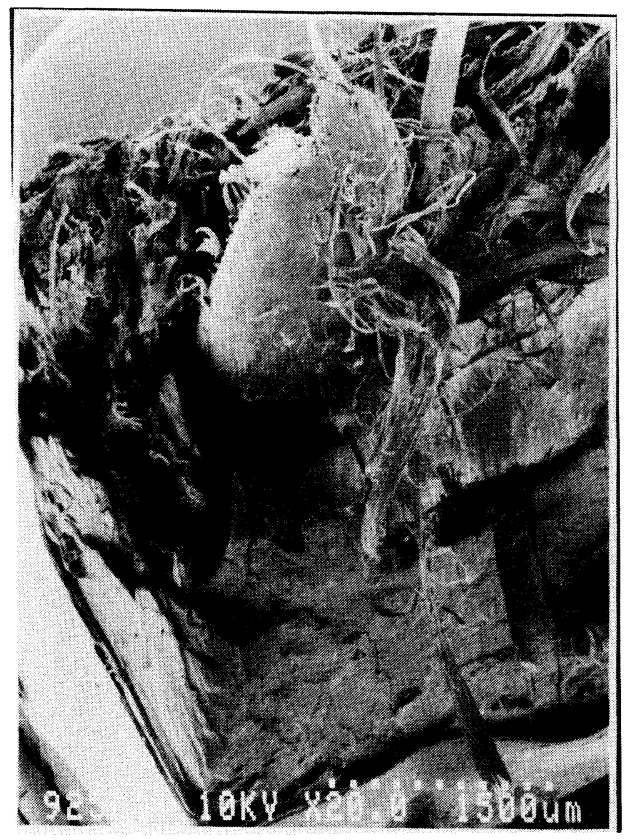

(I)

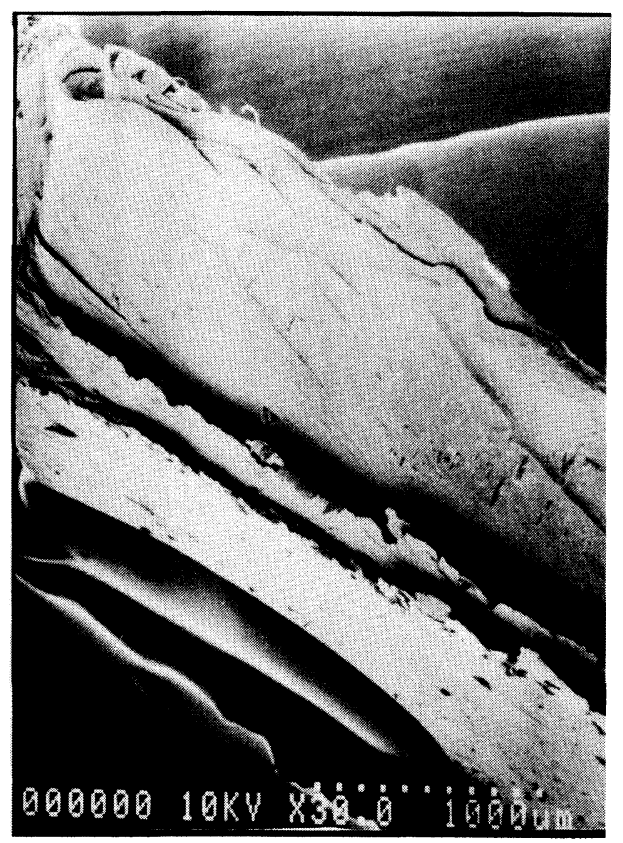

(II)

Figure 11. SEM of flexural fractured injection molded specimens of (I) Me-HQ/BB/NDA $(m / n=92.5 / 7.5)(36 \mathrm{GPa}, F=0.82),(20 \times)$ and (II) $\mathrm{Me}-\mathrm{HQ} / \mathrm{BB} / \mathrm{NDA}(m / n=95 / 5)(47 \mathrm{GPa}, F=0.56),(30 \times)$.

Table II. Thermal properties and modulus of $\mathrm{Ph}-\mathrm{HQ} / \mathrm{HQ}(m / n=10 / 0)$ and $\mathrm{Ph}-\mathrm{HQ} / \mathrm{HQ} / \mathrm{BB}(m / n=5 / 5)^{\mathrm{a}}$

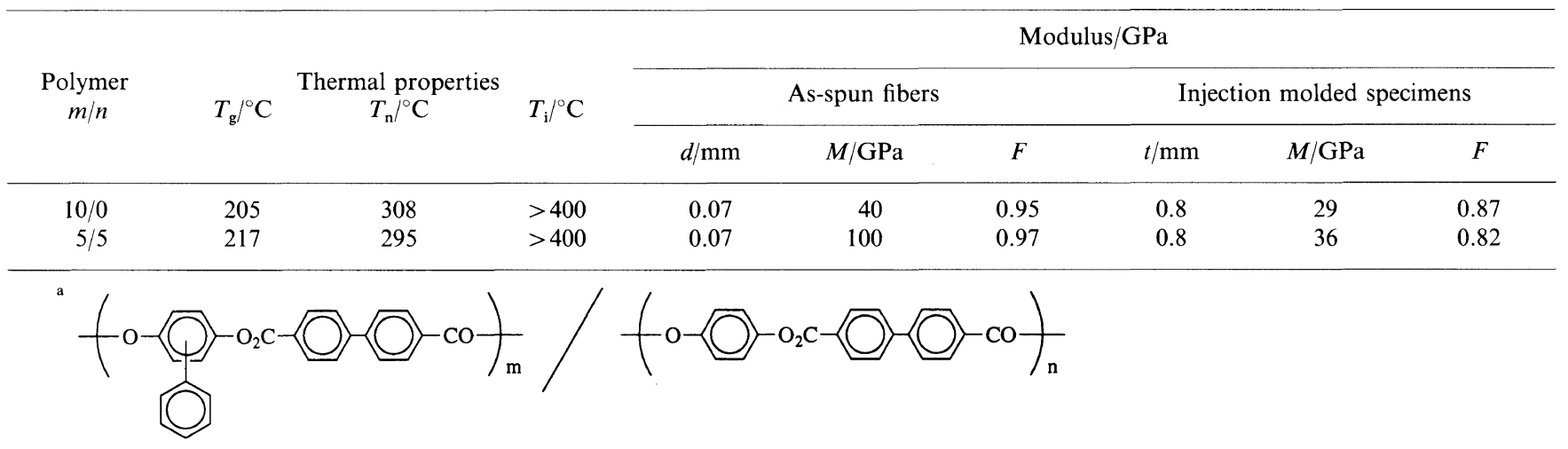

with $m / n=92.5 / 7.5$ in spite of the lower $F$ value, due to the higher rigidity of the polymer chain. Though flexural fractured injection molded specimens of $\mathrm{Me}-\mathrm{HQ} / \mathrm{BB} /$ NDA with $m / n=92.5 / 7.5$ exhibited many fibrils, MeHQ/BB/NDA with $m / n=95 / 5$ exhibited very few fibrils than as shown in Figure 11. ${ }^{16}$

In order to achieve the higher moduli of injection molded specimens, we studied copolymerization of $\mathrm{Ph}$ $\mathrm{HQ} / \mathrm{HQ} / \mathrm{BB}$ as shown in Table II. ${ }^{15}$ As-spun fibers of $\mathrm{Ph}-\mathrm{HQ} / \mathrm{HQ} / \mathrm{BB}$ with $m / n=50 / 50$ exhibited a much higher modulus than $\mathrm{Ph}-\mathrm{HQ} / \mathrm{BB}$ due to the increased $F$ value and rigidity of the polymer chain. Injection molded specimens of $\mathrm{Ph}-\mathrm{HQ} / \mathrm{HQ} / \mathrm{BB}$ with $m / n=50 / 50$ exhibited a much higher modulus than that of $\mathrm{Ph}-\mathrm{HQ} / \mathrm{BB}$ due to the increased rigidity and packing density of the polymer chain by copolymerization on HQ. However, $F$ value of injection molded specimens of $\mathrm{Ph}-\mathrm{HQ} / \mathrm{HQ} / \mathrm{BB}(m / n=$ $50 / 50)$ was not much higher than that of $\mathrm{Ph}-\mathrm{HQ} / \mathrm{BB}$.

Thus, both the rigidity and packing density of the polymer chain seem to be more influential factors than $F$ values to achieve a high modulus of injection molded specimens. Figure 12 shows the relationship between the

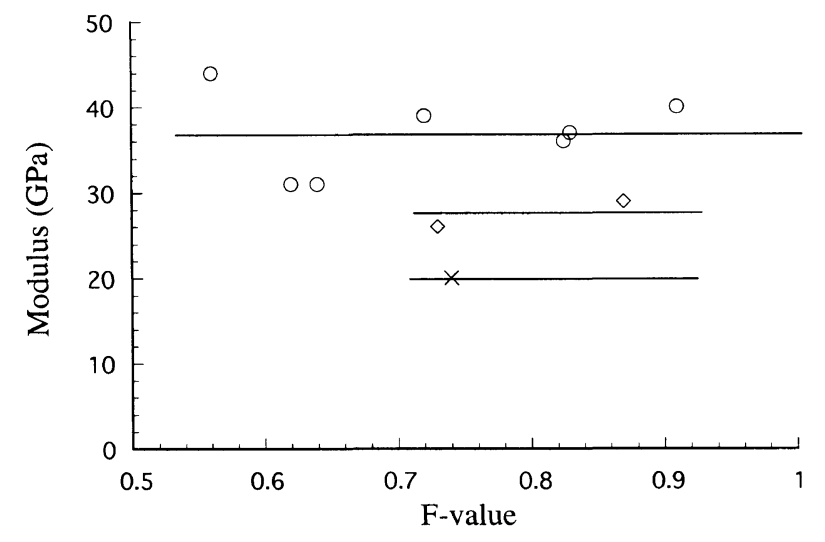

Figure 12. Flexural moduli and $F$ of injection molded specimens. $O$, Me-HQ/BB and copolyarylates; $\diamond, \mathrm{Ph}-\mathrm{HQ} / \mathrm{BB}$ and copolyarylates; $\times, \mathrm{CP}-\mathrm{HQ} / \mathrm{BB}$.

moduli of substituted HQs/BB and substituted HQs/BB modified with DHB, HQ, 2,6-dihydroxynaphthalene (DHN), NDA, Cl-PEC, and TA. 19,13,22,14,20,21 We could find no relationship between them.

Thus, influential factors to obtain high modulus of Polym. J., Vol. 28, No. 5, 1996 
injection molded specimens are as follows: (1) the stability of liquid crystallinity; (2) the rigidity of polymer chain; (3) the packing density of polymer chain.

\section{CONCLUSIONS}

In order to obtain high modulus as-spun fibers, the stability of liquid crystallinity, rigidity of polymer chain, and degree of elongational flow orientation ( $F$ value) are influential factors. The influential factors to obtain high modulus of injection molded specimens are the stability of liquid crystallinity, rigidity of polymer chain and packing density of the polymer chain.

Acknowledgment. This work was performed under the management of Research Association for Basic Polymer Technology as a part of R \& D of Basic Technology for Future Industries sponsored by NEDO.

\section{REFERENCES}

1. J. Majnusz, J. M. Catala, and R. W. Lenz, Eur. Polym. J., 19, 1043 (1983).

2. R. W. Lenz and J.-I. Jin, Macromolecules, 14, 1405 (1981).

3. R. W. Lenz and J.-I. Jin, Br. Polym. J., (Dec.), 132 (1980).

4. J. Majunusz and R. W. Lenz, Eur. Polym. J., 21, 565 (1985).

5. H. R. Dicke and R.W. Lenz, J. Polym. Sci., Polym. Chem. Ed., 21, 2581 (1983).
6. J.-I. Jin, S. Antoun, C. Ober, and R. W. Lenz, Br. Polym. J., (Dec.), 132 (1980)

7. S. Anton, R. W. Lenz, and J.-I. Jin, J. Polym. Sci., Polym. Chem. Ed., 19, 1901 (1981).

8. H. R. Kricherdorf and G. Schwarz, Makromol. Chem., 188, 1281(1987).

9. M. A. Osman, Macromolecules, 19, 1824 (1986).

10. W. R. Krigbaum, H. Hakemi, and R. Kotek, Macromolecules, 18, 965 (1985)

11. W. Brueggig, U. Kampschulte, H.-W. Schmidt, and W. Heitz, Makromol. Chem., 190, 2755 (1989).

12. H. R. Kricherdorf and J. Engelhardt, J. Polym. Sci., Polym. Chem. Ed., 28, 2335 (1990).

13. W. J. Jackson, Jr., Contemp. Topics, Polym. Sci., 5, 177 (1984).

14. T. Inoue, "Progress in Pacific Polymer Science," Vol. 2, SpringVerlag, 1992, p 261.

15. T. Inoue and N. Tabata, Mol. Cryst. Liq. Cryst., 254, 417 (1994).

16. T. Inoue, T. Yamanaka, N. Tabata, and S. Okita, "High Performance Polymers," 7, 303 (1995).

17. T. Inoue, M. Okamoto, and T. Hirai, Kobunshi Ronbunshu, 43, 253 (1986)

18. T. Inoue, M. Okamoto, and T. Hirai, Kobunshi Ronbunshu, 43, $261(1986)$

19. T. Inoue, T. Yamanaka, and M. Okamoto, Koubunshi Ronbunshu, 44, 661 (1988)

20. T. Inoue, N. Goto, N. Tabata, T. Yamanaka, and T. Tanaka, Kobunshi Ronbunshu, 48, 969 (1992).

21. T. Inoue and T. Yamanaka, Kobunshi Ronbunshu, 45, 783 (1988).

22. T. Inoue and M. Okamoto, Kobunshi Ronbunshu, 44, 151 (1987).

23. T. Inoue, N. Goto, N. Tabata, T. Yamanaka, and T. Tanaka, Kobunshi Ronbunshu, 46, 75 (1989).

24. T. Inoue, T. Yamanaka, N. Goto, N. Tabata, and T. Tanaka, Kobunshi Ronbunshu, 48, 765 (1991). 